\title{
Systematic Review \\ Physics Forceps in Tooth Extraction-A Systematic Review of Randomized Controlled Trials
}

\author{
Krishnamachari Janani ${ }^{1}\left(\mathbb{D}\right.$, Kavalipurapu Venkata Teja ${ }^{2}$ (D), Mohammad Khursheed Alam ${ }^{3,4,5}$, \\ Ahmed Ismail Nagy ${ }^{6}\left(\mathbb{D}\right.$, Sulphi Abdul Basheer ${ }^{7}$, Kumar Chandan Srivastava ${ }^{6, * \mathbb{D}}$, Hala A. Hosni ${ }^{6}$, Jerry Jose ${ }^{2} \mathbb{D}$ \\ and Deepti Shrivastava ${ }^{3, *(\mathbb{D})}$
}

1 Department of Conservative Dentistry and Endodontics, SRM Dental College, SRM Institute of Science \& Technology, Chennai 600077, India; jananik6@srmist.edu.in

2 Department of Conservative Dentistry and Endodontics, Saveetha Dental College \& Hospitals, Saveetha Institute of Medical \& Technical Sciences, Saveetha University, Chennai 600077, India; venkatatejak.sdc@saveetha.com (K.V.T.); jerryjosekavungal@gmail.com (J.J.)

3 Department of Preventive Dentistry, College of Dentistry, Jouf University, Sakaka 72345, Saudi Arabia; mkalam@ju.edu.sa

4 Center for Transdisciplinary Research (CFTR), Saveetha Dental College, Saveetha Institute of Medical and Technical Sciences, Saveetha University, Chennai 600077, India

5 Department of Public Health, Faculty of Allied Health Sciences, Daffodil lnternational University, Dhaka 1207, Bangladesh

6 Department of Oral \& Maxillofacial Surgery \& Diagnostic Sciences, College of Dentistry, Jouf University, Sakaka 72345, Saudi Arabia; dr.ahmed.nagy@jodent.org (A.I.N.); dr.hala.hosni@jodent.org (H.A.H.)

7 Department of Oral and Maxillofacial Surgery, College of Dentistry, King Khalid University, Abha 62529, Saudi Arabia; subasheer@kku.edu.sa

check for updates

Citation: Janani, K.; Teja, K.V.; Alam, M.K.; Nagy, A.I.; Basheer, S.A.; Srivastava, K.C.; Hosni, H.A.; Jose, J.; Shrivastava, D. Physics Forceps in Tooth Extraction-A Systematic Review of Randomized Controlled Trials. Appl. Sci. 2022, 12, 254. https://doi.org/10.3390/ app12010254

Academic Editor: Gaetano Isola

Received: 2 December 2021

Accepted: 25 December 2021

Published: 28 December 2021

Publisher's Note: MDPI stays neutral with regard to jurisdictional claims in published maps and institutional affiliations.

Copyright: () 2021 by the authors. Licensee MDPI, Basel, Switzerland. This article is an open access article distributed under the terms and conditions of the Creative Commons Attribution (CC BY) license (https:// creativecommons.org/licenses/by/ $4.0 /)$.

* Correspondence: drkcs.omr@gmail.com (K.C.S.); sdeepti20@gmail.com (D.S.)

\begin{abstract}
The present systematic review aims to evaluate the efficiency of Physics forceps over the conventional forceps for the extraction of a tooth. The study began with targeted electronic searches of MEDLINE, PubMed, Cochrane, Science Direct and Google Scholar databases. All selected articles were reviewed by four independent reviewers for eligibility. The Cochrane Risk of Bias tool was used to analyze the studies for bias. Due to heterogeneity of the selected studies, a meta-analysis of the current systematic review was not possible. A total of five studies were considered for the final analysis. The risk of bias showed high risk for all five included articles. Various parameters, such as fracture of the root, dry socket, healing, pain, postoperative infection, crown fractures, buccal bone fractures, extraction time, gingival and marginal bone loss, gingival laceration, bleeding and healing were assessed. Based on the data available, there is an insufficient quality of evidence to conclude the superiority of the Physics forceps over conventional forceps.
\end{abstract}

Keywords: conventional forceps; extraction; Physics forceps; oral surgery

\section{Introduction}

Exodontia is a common procedure carried out by dentists in their routine clinical practice. The ultimate goal of tooth extraction should aim to cause the least possible amount of trauma to the dentoalveolar structures. In routine dental practice, conventional forceps are employed to carry out tooth extractions. They work on the class two lever principle, which is connected to a hinge [1]. In other words, they tend to provide a pulling force to squeeze out the tooth from the socket. Atraumatic tooth extractions have always been a matter of interest to dentists, as they minimize marginal bone loss, cause minimal soft tissue and alveolar bone damage and, ultimately, also prevent post-operative complications [2,3]. Atraumatic extraction preserves bone, gingival architecture and allows for the option of immediate or future dental implant placement. In recent years, various efforts have been made to minimize traumatic extraction, thereby preventing post-operative complications. 
Physics forceps are one such innovation that was invented in the year 2004. This device works on the biomechanical principle without squeezing, grasping, twisting and pulling forces to perform atraumatic extraction. It was Dr. Richard Golden who introduced and invented the concept of Physics forceps [4]. This instrument process preserves the buccal bone, cortical plates and claims to eliminate root tip fractures. Physics forceps have a beak and bumper design that facilitates atraumatic extraction. They utilize only wrist movement based on the first-order lever principle without harming the buccal alveolar bone. To use Physics forceps for exodontia, a minimum of $3 \mathrm{~mm}$ of remaining tooth structure is mandatory. Since it has already been established that conventional forceps induce more traumatic extraction, the need for an alternative has gained importance. With the advent of Physics forceps with its unique design and biomechanical principle, we intended to evaluate their efficiency by assessing the following criteria, such as crown-root fracture, bone plate fracture and intra and post-operative complications. Hence, the aim of this systematic review was to evaluate the efficiency of Physics forceps over conventional forceps for the extraction of a tooth. The null hypothesis states that the Physics forceps are not superior to the conventional forceps.

\section{Materials and Methods}

The Preferred Reporting Items for Systematic Review and Meta-Analysis [5] and Cochrane Handbook for Systematic Reviews of Intervention guidelines [6] were followed in this systematic review.

\subsection{Criteria for Eligibility}

The PICOS (patient, intervention, comparison, outcome, type of study) framework was used to identify studies. Type of study and participants: randomized controlled trial comparing Physics forceps with conventional forceps were included in the present systematic review. There were no gender restrictions considered in the current review. The excluded studies were observational research, case reports, narrative reviews, animal studies and narrative reviews. Intervention and comparison: Physics forceps in the intervention group and conventional forceps in the control group. Outcome: the various outcomes considered in the current review included fracture of the root, dry socket, healing, pain, post-operative infection, crown fractures, buccal bone fractures, extraction time, gingival and marginal bone loss, gingival laceration, bleeding and healing. Study design: only randomized clinical trials were included.

\subsection{Methods for Identifying Studies Using Search Engines}

There was no restriction on the language of the published papers. The MEDLINE, and PubMed search strategy, which included keywords and heading terms, were performed (Figure 1).

\subsection{Searches Using Electronic Database}

Until March 2020, the search was performed in the databases of MEDLINE, Cochrane Central Register of Controlled Trials, Google Scholar, Science Direct and PubMed.

\subsection{Reference List}

Hand searching was performed from the reference lists of the included studies. We also looked for abstracts from the "International Association for Dental Research Meetings" (2001-present) that were available.

The studies that were included in this review were chosen using a two-step approach. To begin, the titles and abstracts of research were examined to see if they satisfied the inclusion criteria. The full texts of all studies that met the criteria were retrieved. Using the predetermined criteria, four reviewers independently appraised the research for relevance. Any differences of opinion were settled through discussion. 


\subsection{Data Collection}

The below-mentioned data were retrieved from each study using a data extraction form. Sample size, study, year of study, type of teeth, anesthesia used for exodontia, intervention and comparison used and outcomes were assessed.

\begin{tabular}{|c|c|c|c|c|}
\hline \multicolumn{3}{|l|}{ History } & \multicolumn{2}{|c|}{ ownload history Clear history } \\
\hline Search & Add to builder & Query & Items found & Time \\
\hline$\# 26$ & $\underline{\text { Add }}$ & $\begin{array}{l}\text { Search (((()((((human teeth) OR extraction) OR tooth extraction) OR third molar teeth) OR permanent } \\
\text { teeth) OR orthodontic extraction)) AND (((physics forceps) OR physics forceps for extraction) OR } \\
\text { physics forceps for dental extraction)) AND (((conventional forceps) OR conventional forceps for } \\
\text { dental extraction) OR conventional forceps for extraction)) AND (((((crown fracture) OR root fracture) } \\
\text { OR apical root fracture) OR alveolar bone fracture) OR gingival tear) OR soft tissue injury) }\end{array}$ & $\underline{2}$ & $00: 20: 34$ \\
\hline$\# 25$ & $\underline{\text { Add }}$ & $\begin{array}{l}\text { Search ((( ((crown fracture) OR root fracture) OR apical root fracture) OR alveolar bone fracture) OR } \\
\text { gingival tear) OR soft tissue injury }\end{array}$ & $\underline{29513}$ & $00: 20: 18$ \\
\hline$\# 24$ & Add & Search soft tissue injury & $\underline{22131}$ & $00: 19: 49$ \\
\hline$\# 23$ & $\underline{\text { Add }}$ & Search gingival tear & $\underline{49}$ & $00: 19: 12$ \\
\hline$\# 22$ & $\underline{\text { Add }}$ & Search alveolar bone fracture & $\underline{1417}$ & 00:19:02 \\
\hline$\# 21$ & $\underline{\text { Add }}$ & Search apical root fracture & $\underline{499}$ & $00: 18: 51$ \\
\hline$\# 20$ & $\underline{\text { Add }}$ & Search root fracture & $\underline{4390}$ & $00: 18: 38$ \\
\hline$\# 19$ & $\underline{\text { Add }}$ & Search crown fracture & $\underline{3415}$ & $00: 18: 27$ \\
\hline$\# 18$ & $\underline{\text { Add }}$ & $\begin{array}{l}\text { Search ((conventional forceps) OR conventional forceps for dental extraction) OR conventional } \\
\text { forceps for extraction }\end{array}$ & $\underline{2921}$ & $00: 17: 42$ \\
\hline$\# 17$ & $\underline{\text { Add }}$ & Search conventional forceps for extraction & $\underline{117}$ & 00:17:22 \\
\hline$\# 16$ & $\underline{\text { Add }}$ & Search conventional forceps for dental extraction & $\underline{35}$ & 00:16:54 \\
\hline$\# 15$ & $\underline{\text { Add }}$ & Search conventional forceps & $\underline{2921}$ & 00:16:30 \\
\hline$\# 14$ & Add & Search ((physics forceps) OR physics forceps for extraction) OR physics forceps for dental extraction & $\underline{2336}$ & 00:16:11 \\
\hline$\# 13$ & Add & Search physics forceps for dental extraction & $\underline{13}$ & 00:15:57 \\
\hline$\# 12$ & Add & Search physics forceps for extraction & $\underline{84}$ & 00:15:34 \\
\hline$\# 11$ & $\underline{\text { Add }}$ & Search physics forceps & $\underline{2336}$ & $00: 15: 20$ \\
\hline$\# 10$ & $\underline{\text { Add }}$ & $\begin{array}{l}\text { Search (((((human teeth) OR extraction) OR tooth extraction) OR third molar teeth) OR permanent } \\
\text { teeth) OR orthodontic extraction }\end{array}$ & $\underline{440765}$ & 00:15:02 \\
\hline$\# 9$ & $\underline{\text { Add }}$ & Search orthodontic extraction & $\underline{4269}$ & $00: 14: 17$ \\
\hline$\# 8$ & $\underline{\text { Add }}$ & Search permanent teeth & $\underline{19235}$ & $00: 13: 36$ \\
\hline$\# 7$ & Add & Search third molar teeth & $\underline{9384}$ & $00: 13: 22$ \\
\hline \#6 & $\underline{\text { Add }}$ & Search tooth extraction & $\underline{25470}$ & 00:13:08 \\
\hline \#5 & $\underline{\text { Add }}$ & Search extraction & $\underline{274571}$ & $00: 12: 50$ \\
\hline$\# 4$ & $\underline{\text { Add }}$ & Search human teeth & $\underline{185362}$ & $00: 12: 34$ \\
\hline
\end{tabular}

Figure 1. Search Strategy.

\subsection{Risk of Bias Assessment}

The Cochrane risk of bias tool was used to assess the risk of bias in the included studies by two reviewers working independently. The risk of bias for the included studies was graded as low, unclear or high. Random sequence generation (e.g., computer-based or random number table), allocation concealment (e.g., central randomization or sealed opaque envelopes), blinding of participants and personnel, blinding of outcome assessment, incomplete outcome data, selective reporting (e.g., not reporting some outcomes) and other potential sources of bias were evaluated.

The assessment of the risk of bias in the included studies was performed independently by two reviewers using the Cochrane risk of bias tool. The included studies were awarded an overall risk of bias grade of either low, unclear or high. We assessed the following domains: random sequence generation (e.g., computer-based or random number table), allocation concealment (e.g., central randomization or sealed opaque envelopes), blinding of participants and personnel, blinding of outcome assessment, incomplete outcome data, selective reporting (e.g., not reporting some outcomes), and other potential sources of bias. To evaluate the risk of bias for each outcome, we used risk of bias assessments for each study.

1. We considered a study to be a low risk of bias if it had a low risk of bias across all domains.

2. We considered a study to have an unclear risk of bias if we determined that it had an unclear risk of bias for one or more domains, but no domain was considered high risk.

3. We considered a study to be a high risk of bias if it had a high risk of bias in one or more domains. 


\subsection{Evaluation of Heterogeneity}

We investigated clinical heterogeneity in terms of participants, intervention and outcome measurement. The results could not be pooled for meta-analysis due to differences in study characteristics. As a result, the studies were summarized in a descriptive manner.

\section{Results}

The search showed nine articles. Among these, only five articles fulfilled the inclusion criteria [7-11] (Figure 2). A list of excluded articles is also mentioned (Table 1).

\section{Identification of studies via databases}

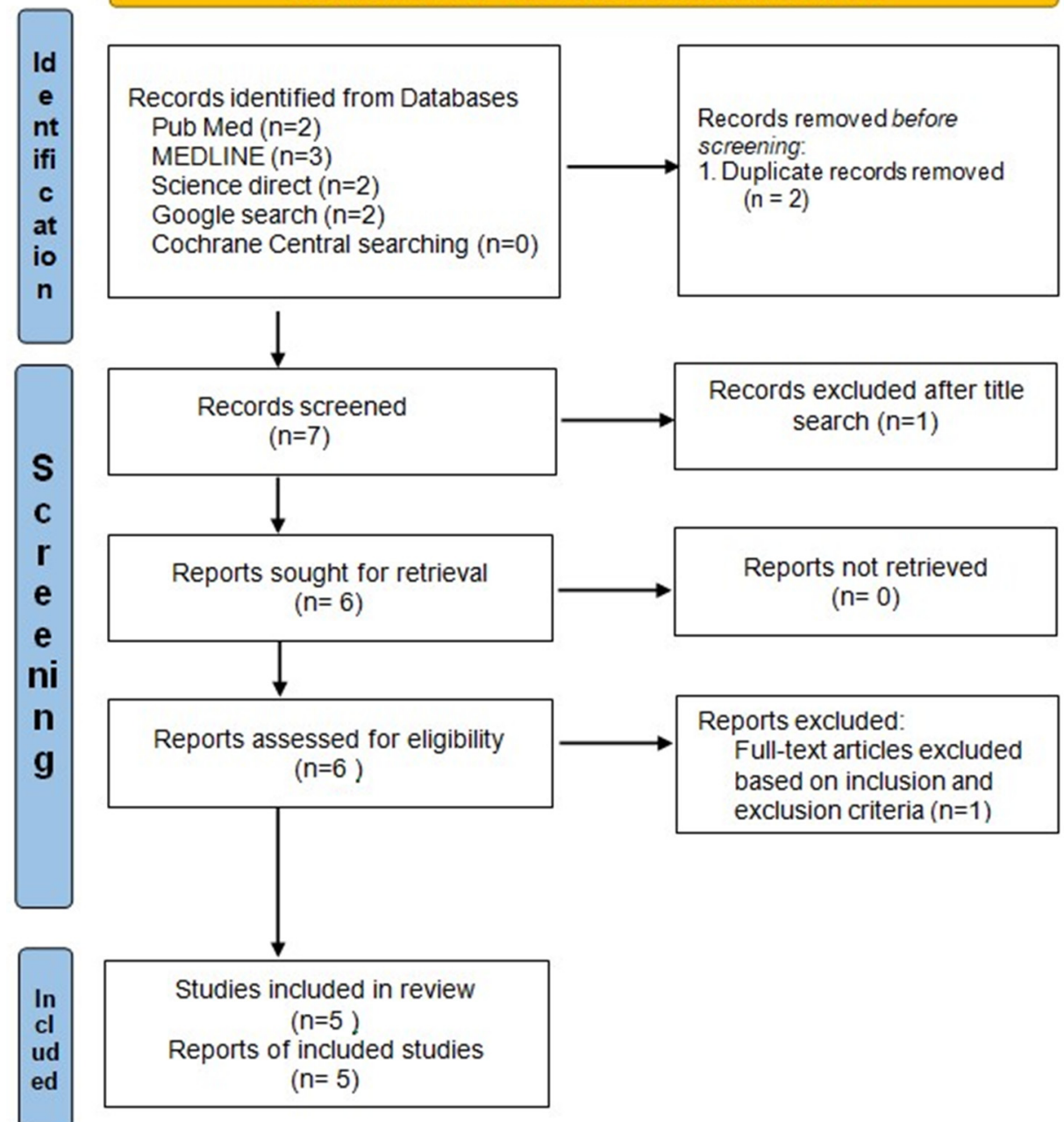

Figure 2. PRISMA Flowchart.

Table 1. Characteristics of excluded articles.

\begin{tabular}{ccc}
\hline Author & Year & Reason for Exclusion \\
\hline $\begin{array}{c}\text { Maddalone M } \\
\text { Raghu K }\end{array}$ & 2003 & The scope of the article does not match with the inclusion criteria \\
& 2020 & No comparison between Physics forceps and conventional forceps \\
\hline
\end{tabular}

\subsection{Study Characteristics}

Characteristics of the included study were mentioned in Tables 2 and 3 Out of the included articles, four studies were conducted in India. Hariharan et al. [7] executed sample size calculations and mentioned the method they employed, whereas the other research did not specify the same. There were no funding sources for any of the studies. The age of the patient was mentioned in four studies, whereas only one study did not mention the age [9]. 
The study design differed among the included studies, where two studies performed a split mouth trial. The sample size ranged from 28-200. Teeth indicated for orthodontic extraction were included in two studies $[7,10]$, whereas other studies employed a carious, sound and mobile tooth for extraction. However, one study [9] did not mention the type of teeth subjected for extraction. There was one study [11] which included all the teeth for extraction. With regard to tooth type, a maxillary premolar was subjected to extraction in one study [7]. On the other hand, maxillary and mandibular premolar teeth were subjected for extraction in another study [10]. In a different study, mandibular teeth from a second premolar to premolar were employed for extraction [8]. None of the studies mentioned the operator who performed the extraction. Furthermore, none of the articles had their protocols registered in clinical trials [12].

\subsection{Risk of Bias in Included Studies}

None of the studies performed allocation bias and only one study mentioned about the assessor bias [7]. Only two studies performed randomization in the included article. Overall, all the included studies had a high risk of bias (Figure 3).

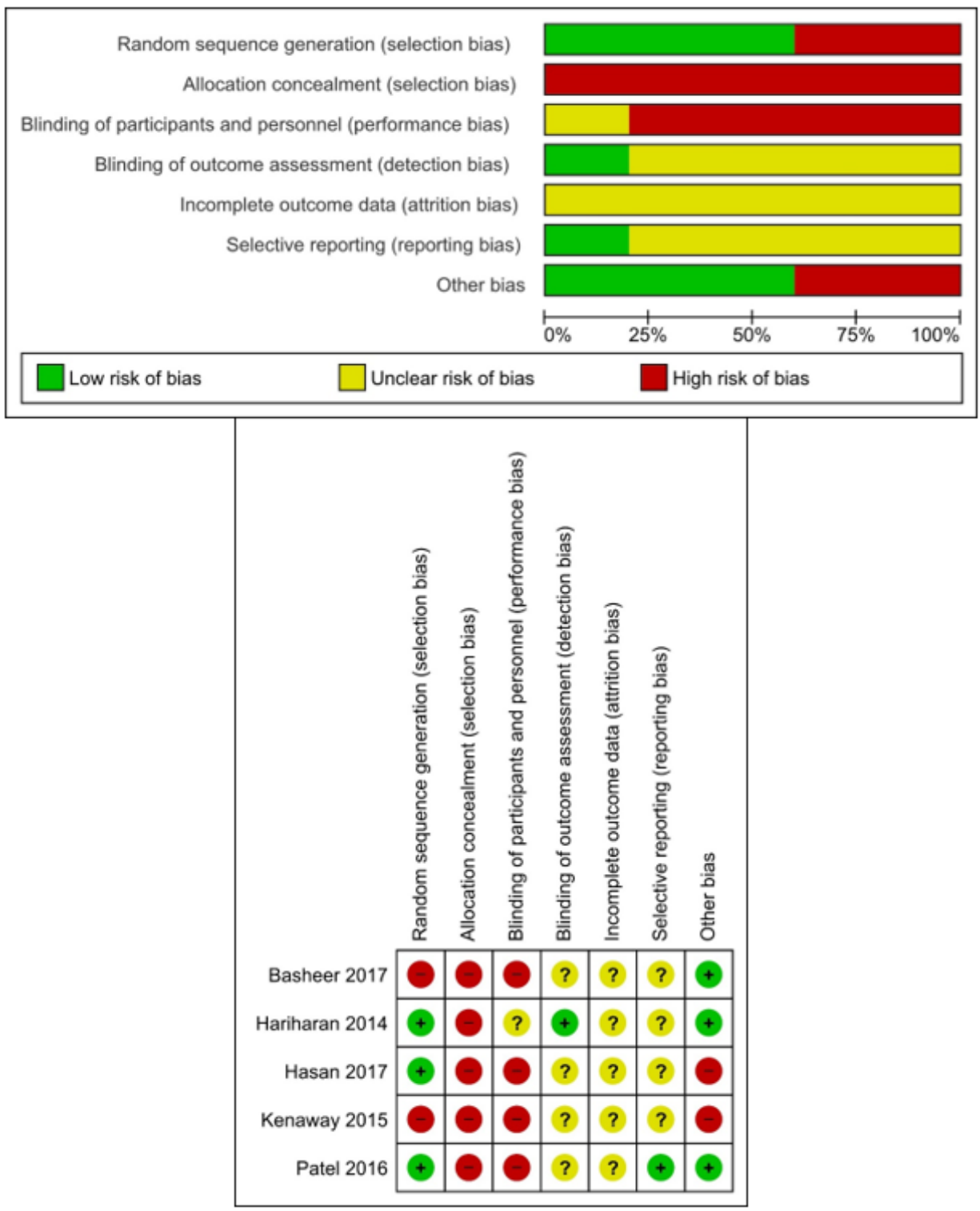

Figure 3. Risk of bias. 
Table 2. Characteristics of included articles.

\begin{tabular}{|c|c|c|c|c|c|c|c|c|c|}
\hline Author/Year & Country & Study Design & Sample Size & $\begin{array}{c}\text { Pre-Operative Status of } \\
\text { Tooth }\end{array}$ & Anesthesia & Extracted Teeth & Intervention & Comparison & Parameter Assessed \\
\hline Hariharan 2014 & India & $\begin{array}{l}\text { Randomized split } \\
\text { mouth clinical trial }\end{array}$ & $\begin{array}{c}n=54 \text { teeth } \\
(n=27 \text { per group })\end{array}$ & $\begin{array}{l}\text { Healthy tooth indicated } \\
\text { for orthodontic extraction }\end{array}$ & $\begin{array}{c}1.8 \mathrm{~mL} \text { of } 1: 200,000 \text { units } \\
\text { as Xylocaine }\end{array}$ & Maxillary premolars & Physics forceps & $\begin{array}{l}\text { Universal extraction } \\
\text { forceps }\end{array}$ & $\begin{array}{c}\text { Fracture of root, } \\
\text { dry socket, } \\
\text { healing, pain, post-operative } \\
\text { infection }\end{array}$ \\
\hline Kenawy 2015 & India & $\begin{array}{c}\text { Randomized clinical } \\
\text { trial }\end{array}$ & $\begin{array}{c}n=200 \text { patients } \\
(n=100 \text { per group })\end{array}$ & $\begin{array}{l}\text { Teeth indicated for } \\
\text { extraction with } 3 \mathrm{~mm} \text { or } \\
\text { more of intact tooth } \\
\text { structure above the } \\
\text { gingival margin }\end{array}$ & $\begin{array}{c}2 \% \text { mepivacaine HCL } \\
\text { with } \\
1: 20,000 \text { levonordefrine }\end{array}$ & $\begin{array}{l}\text { Maxillary and } \\
\text { mandibular teeth } \\
\text { (Both anterior and } \\
\text { posterior) }\end{array}$ & Physics forceps & $\begin{array}{l}\text { Conventional } \\
\text { forceps }\end{array}$ & $\begin{array}{l}\text { Crown fractures, buccal bone } \\
\text { fractures, fractured roots }\end{array}$ \\
\hline Patel 2016 & India & $\begin{array}{l}\text { Randomized split } \\
\text { mouth clinical trial }\end{array}$ & $\begin{array}{c}n=11 \text { patients } \\
n=42 \text { teeth } \\
(n=21 \text { per group })\end{array}$ & $\begin{array}{l}\text { Healthy tooth indicated } \\
\text { for orthodontic extraction }\end{array}$ & $\begin{array}{l}\text { 1:80,000 Lignocaine } \\
\text { Hydrochloride \& } \\
\text { adrenaline }\end{array}$ & $\begin{array}{l}\text { Maxillary and } \\
\text { mandibular } \\
\text { premolars }\end{array}$ & Physics forceps & $\begin{array}{l}\text { Conventional } \\
\text { forceps }\end{array}$ & $\begin{array}{c}\text { Extraction time, root fracture, } \\
\text { buccal cortical plate fracture, } \\
\text { gingival and marginal bone } \\
\text { loss, pain }\end{array}$ \\
\hline Basheer 2017 & India & $\begin{array}{c}\text { Randomized clinical } \\
\text { trial }\end{array}$ & $\begin{array}{c}n=100 \text { patients } \\
(n=50 \text { per group })\end{array}$ & $\begin{array}{l}\text { Teeth indicated for } \\
\text { extraction with } 3 \mathrm{~mm} \text { or } \\
\text { more of intact tooth } \\
\text { structure above the } \\
\text { gingival margin }\end{array}$ & $\begin{array}{l}2 \% \text { lignocaine with } \\
\text { adrenaline }\end{array}$ & Not mentioned & Physics forceps & $\begin{array}{l}\text { Conventional } \\
\text { forceps }\end{array}$ & $\begin{array}{c}\text { Fracture of tooth, fracture of } \\
\text { buccal cortical plate, gingival } \\
\text { laceration, bleeding, pain, } \\
\text { healing }\end{array}$ \\
\hline Hasan 2017 & Iraq & $\begin{array}{c}\text { Randomized clinical } \\
\text { trial }\end{array}$ & $\begin{array}{c}n=28 \text { teeth } \\
(n=14 \text { per group })\end{array}$ & $\begin{array}{l}\text { Teeth indicated for } \\
\text { extraction, both carious } \\
\text { sound and mobile tooth } \\
\text { (grade of mobility not } \\
\text { mentioned) }\end{array}$ & $\begin{array}{l}2 \% \text { lidocaine with } \\
\text { 1:100,000 adrenaline }\end{array}$ & $\begin{array}{l}\text { Mandibular teeth } \\
\text { from second } \\
\text { premolar to } \\
\text { premolar }\end{array}$ & Physics forceps & $\begin{array}{l}\text { Conventional } \\
\text { forceps }\end{array}$ & $\begin{array}{l}\text { Buccal bone fracture, crown } \\
\text { fracture, gingival tearing, } \\
\text { root fracture, time of } \\
\text { extraction }\end{array}$ \\
\hline
\end{tabular}


Table 3. Characteristics of included articles.

\begin{tabular}{|c|c|c|c|c|}
\hline Parameter & Author/Year & Assessment Criteria & Time of Assessment & Outcome Assessment \\
\hline \multirow{3}{*}{ Crown fracture } & Hasan et al. & Yes/No & Intraoperative period & No difference \\
\hline & Hariharan et al. & Yes/No & Intraoperative period & No difference \\
\hline & Kenawy et al. & Yes/No & Intraoperative period & Physics forceps were better than conventional forceps \\
\hline \multirow{3}{*}{ Root fracture } & Kenawy et al. & Yes/No & Intraoperative period & Physics forceps were better than conventional forceps \\
\hline & Hasan et al. & Yes/No & Intraoperative period & No difference \\
\hline & Hariharan et al. & Yes/No & Intraoperative period & No difference \\
\hline \multirow{4}{*}{ Bone plate fracture } & Kenawy et al. & Yes/No & Intraoperative period & No difference \\
\hline & Patel et al. & Yes/No & Intraoperative period & No difference \\
\hline & Hasan et al. & Yes/No & Intraoperative period & No difference \\
\hline & Basheer et al. & Yes/No & Intraoperative period & No difference \\
\hline \multirow{3}{*}{ Extraction time } & Patel et al. & Stopwatch measured at seconds & Intraoperative period & $\pm 48.13 \mathrm{~s}, \pm 37.59 \mathrm{~s}$ for Physics forceps and conventional forceps, respectively \\
\hline & Hasan et al. & Stopwatch measured at minutes & Intraoperative period & $0.38 \mathrm{~min}, 3.97 \mathrm{~min}$ for Physics forceps and conventional forceps, respectively \\
\hline & Hariharan et al. & Stopwatch measured at minutes & Intraoperative period & Operating time using Physics forceps was $29.4 \mathrm{~s}$ and with the universal extraction forceps $43.5 \mathrm{~s}$ \\
\hline Gingival level & & & & $\begin{array}{l}\text { Mean difference in the pre- and post-extraction gingival level using Physics forceps and } \\
\text { conventional forceps was } 0.57 \mathrm{~mm} \text { and } 1.01 \mathrm{~mm} \text {, respectively }\end{array}$ \\
\hline Marginal bone loss & Patel et al. & Williams periodontal probe & At the point of extraction & $\begin{array}{l}\text { Mean difference in the pre- and post-extraction bone level using Physics forceps and conventional } \\
\text { forceps was } 1.26 \mathrm{~mm} \text { and } 1.87 \mathrm{~mm}\end{array}$ \\
\hline \multirow{3}{*}{ Post-operative pain } & Hariharan et al. & 10-point VAS & 1,3 and 7 th day & Physics forceps had significantly less pain on the first post-operative day than the other group \\
\hline & Patel et al. & VAS scale (Not specified) & 1 and 3rd day & Difference in pain score using either forceps was not statistically significant \\
\hline & Basheer et al. & 10-point VAS & Up to 7th day & On 1st \& 2nd day Physics forceps showed a significant reduction in pain. \\
\hline Gingival laceration & Basheer et al. & Yes/No & Until 5th day & No difference \\
\hline Dry socket & Hariharan et al. & Yes/No & $1,3,7$ and 21 days & No difference \\
\hline $\begin{array}{l}\text { Post-operative infections } \\
\text { (redness, swelling, pus } \\
\text { discharge) }\end{array}$ & Hariharan et al. & Yes/No & $1,3,7$ and 21 days & No difference \\
\hline \multirow[b]{2}{*}{ Healing } & Hariharan et al. & Method of assessment not mentioned & $1,3,7$ and 21 days & No difference \\
\hline & Basheer et al. & $\begin{array}{l}\text { Healing of the extraction sockets were evaluated } \\
\text { on 7th day using a 5-point VAS scale }(0 \\
\text { representing normally pink, non-edematous and } 5 \\
\text { representing dry socket) }\end{array}$ & 7th day & Physics forceps were better than conventional forceps \\
\hline
\end{tabular}




\subsubsection{Assessment of Crown Fracture}

Three of the included studies [7,8,11] evaluated the crown fracture. Among them, two studies did not show any difference between the intervention and the control group, whereas one study reported that Physics forceps were better than the conventional forceps (11).

\subsubsection{Assessment of Root Fracture}

Among the articles which were included in the present systematic review, only four studies had assessed the root fracture [7-11]. Three studies out of four did not show any difference between the intervention and control group, whereas one study reported that Physics forceps were better than the conventional forceps [11].

\subsubsection{Assessment of Buccal Bone Plate Fracture}

Among the four articles, all the studies showed no difference between both types of forceps [8-11].

\subsubsection{Extraction Time}

Three studies evaluated the mean time required for extraction [7-10]. All the studies showed that the operating time for the Physics forceps was less than the conventional forceps. One study [10] reported the time in seconds, whereas two other studies reported in minutes.

\subsubsection{Gingival Level and Marginal Bone Loss}

Only one study [10] evaluated the mean difference of gingival and marginal bone loss by assessing both pre- and post-operatively. The Physics forceps showed less gingival level and marginal bone loss compared to the conventional extraction forceps.

\subsubsection{Post-Operative Pain}

Three articles assessed post-operative pain [7-10]. Two studies [7,9] performed a 10-point VAS scale. Patel et al. [10] did mention the type of visual analogue scale (VAS) used in their study, and the outcome did not show any difference with either use of forceps. The other two studies showed no difference in post-operative pain on the first and second day.

\subsubsection{Bleeding and Gingival Laceration}

Only one study [9] evaluated bleeding and laceration until the 5th day of the postoperative period. There was no difference in gingival laceration with the use of either forceps. Regarding post-operative bleeding, the Physics forceps showed reduced bleeding compared to the conventional forceps.

\subsubsection{Post-Operative Complications}

The presence of post-operative complications, such as dry socket, redness, swelling and pus discharge, were evaluated. Only one study [7] evaluated these complications, and the result showed no difference between the use of either forceps.

\subsubsection{Healing}

One study evaluated the post-operative healing rate on the 7th day using the VAS scale. The outcome assessment showed better healing with the Physics forceps than the conventional forceps [9]. Another study [7] evaluated post-operative healing on the 1st, 3rd, 7th and 21st day. However, the method of assessment was not mentioned in the study; there was no difference between the experimental and the control groups.

\section{Discussion}

Physics forceps are an instrument that was invented with the primary focus on bringing minimal traumatic extraction. It uses the mechanism of first-class lever along with the 
principle of creep, thereby providing a mechanical advantage to make dental extraction more efficient [13]. It has a beak and a bumper. The beak is attached to one handle of the forceps, which is placed on the palatal or lingual aspect, and the bumper is attached to another handle, which is placed on the mucogingival junction on the facial or buccal aspect, which acts as a fulcrum during extraction [14].

Due to the fulcrum action, shear and compressive forces are produced when the forceps are applied onto the tooth. Shear forces exert on the lingual aspect, whereas a compressive force exerts on the buccal aspect. The bumper expands the force on the bone and surrounding periodontal ligament, thus reducing the incidence of fracture. This principle is called creep [14]. Moreover, the bumper is covered with silicon, which provides a cushioning effect between the bumper and the oral mucosa [8].

When Physics forceps are applied to the tooth surface, the periodontal ligament causes the release of hyaluronidase, which in turn detaches the periodontal attachment to the alveolus and thereby helps in removal from the socket $[15,16]$ This explains the reason for a less traumatic extraction. A previous report suggests that [17] there is no need to use elevators to raise the mucoperiosteal flap with the use of Physics forceps.

An estimation of sample size is very critical for a clinical trial. The underpowered study tends to impart unreliable results. Moreover, among the included studies, the study that has a very large sample size tends to over inflate the outcome result in a systematic review. Assessment of the pre-operative status of the tooth indicated for extraction is of utmost importance. One study [8] included mobile teeth in the selection criteria, although there was no mention about the grade of mobility. This might be one of the confounding factors influencing the results.

On assessing the extraction time, studies have shown that Physics forceps reduced the extraction time compared to the conventional forceps due to unidirectional constant force. On the other hand, in the case of conventional forceps, the force is exerted by twisting and rotating, thereby increasing the extraction time $[7,18]$. Post-operative pain following the extraction with Physics forceps has been reduced due to a less traumatic extraction. Moreover, complications such as tooth fractures have also been reduced due to a contact unidirectional force exerted. However, it is not possible to arrive at a conclusion with a limited number of studies with poor methodological quality.

In evaluating post-operative pain, it would be appropriate to assess the pre-operative pain scores and then to compare it post-operatively, especially in a symptomatic tooth. None of the studies mentioned the pre-operative pain score. This is another confounding factor influencing the results. In a condition such as a tooth with infected and inflamed pulp and periapical tissue, the role of local anesthesia and the mode of injection technique also plays a significant role. The pre-operative status of such conditions affects post-operative pain [19].

None of the studies mentioned the operator who performed the extraction. Most of the studies were performed in the department of oral and maxillofacial surgery, but the studies did not mention whether the extraction was performed by a post-graduate student or by an experienced dentist. Additionally, experience and training is required to use the Physics forceps for extraction. None of the studies commented on the experience of the operator.

Discussing the risk of bias, blinding of the operator is not appropriate for this type of study, as the operator will definitely know what kind of forceps were used for extraction. However, it is essential to mention about the assessor bias. None of the studies mentioned assessor bias except one study [7]. This is also one of the confounding factors.

The preservation of marginal bone is very important when we consider prosthetic replacement, especially for the placement of an implant. Only one study [10] mentioned about this parameter. It was evident that the use of the Physics forceps was beneficial in this aspect.

While assessing healing, only two studies discussed this factor, and both the studies showed different outcome results. 


\title{
5. Quality of Evidence
}

Overall, we found low-quality evidence from the included studies. Due to the risk of bias and lack of precision in the included studies, we degraded the quality of evidence. Due to the low quality of the evidence, more research is extremely likely to have a significant impact on our confidence in the effect estimate and to change the estimate. There are some limitations in the present systematic review. First and foremost, the evidence in this review was deemed insufficient. This could be seen as the major flaw in this research. Second, the sample sizes of the studies that were included were all different. Third, there was no blinding of the assessor.

\section{Future Implications}

Since the present systematic review did not report sufficient data, future studies should focus on more randomized clinical trial needs assessing all the parameters with high methodological and reporting quality.

\section{Conclusions}

Based on the available data, there is an insufficient quality of evidence to conclude the superiority of the Physics forceps over the conventional forceps.

\begin{abstract}
Author Contributions: Conceptualization, K.J., K.V.T. and J.J.; methodology, K.J., J.J. and K.V.T.; software, M.K.A. and A.I.N.; validation, H.A.H., M.K.A. and A.I.N.; formal analysis, K.V.T. and K.C.S.; investigation, K.J., K.V.T. and J.J.; resources K.J., K.V.T., K.C.S. and D.S; writing-original draft preparation, K.J., K.V.T., K.C.S. and D.S.; writing-review and editing, K.J., K.V.T., K.C.S., D.S., A.I.N., M.K.A., S.A.B., H.A.H. and J.J.A; visualization, H.A.H., S.A.B. and M.K.A.; supervision K.C.S.; funding acquisition, K.C.S. and K.V.T. All authors have read and agreed to the published version of the manuscript.
\end{abstract}

Funding: This research received no external funding.

Institutional Review Board Statement: Not applicable.

Informed Consent Statement: Not applicable.

Data Availability Statement: The data set used in the current study will be made available on reasonable request.

Conflicts of Interest: The author declares no conflict of interest.

\section{References}

1. Feck, A. Predictable, atraumatic dental extractions. Dent. Econ. 2010, 100, 1-4.

2. Irinakis, T. Rationale for Socket Preservation after Extraction of a Single-Rooted Tooth when Planning for Future Implant Placement. J. Can. Dent. Assoc. 2006, 72, 917-922. [PubMed]

3. El Chaar, E.S. Immediate placement and provisionalization of implant-supported, single-tooth restorations: A retrospective study. Int. J. Periodontics Restor. Dent. 2011, 31, 409-419. [CrossRef] [PubMed]

4. Raghu, K.; Selvakumar, S.; Muthukumar, R.; Thangavelu, A.; Sathyanarayanan, R.; Mani, M.; Balasubramaniam, M. Beak and bumper-Physics forceps: Evaluation of new technique in extraction. Indian J. Dent. Res. 2020, 31, 4. [CrossRef] [PubMed]

5. Moher, D.; Liberati, A.; Tetzlaff, J.; Altman, D.G.; The PRISMA Group. Preferred Reporting Items for Systematic Reviews and Meta-Analyses: The PRISMA Statement. PLoS Med. 2009, 21, e1000097.

6. Higgins, J.P.; Altman, D.G.; Gøtzsche, P.C.; Jüni, P.; Moher, D.; Oxman, A.D.; Savović, J.; Schulz, K.F.; Weeks, L.; Sterne, J.A. The Cochrane Collaboration's tool for assessing risk of bias in randomised trials. BMJ 2011, 343, d5928. [CrossRef] [PubMed]

7. Hariharan, S.; Narayanan, V.; Soh, C.L. Split-mouth comparison of Physics forceps and extraction forceps in orthodontic extraction of upper premolars. Br. J. Oral Maxillofac. Surg. 2014, 52, e137-e140. [CrossRef] [PubMed]

8. Hasan, A.M. The Efficiency of Physics Forceps In Comparison To The Conventional Dental Extraction Forceps: A randomized Clinical Trial. J. Baghdad Coll. Dent. 2019, 31, 52-59. [CrossRef]

9. Basheer, S.A. Comparative evaluation between physics forceps and conventional extraction forceps in extraction of maxillary molars. Int. J. Appl. Dent. Sci. 2017, 34, 152-154.

10. Patel, H.S.; Managutti, A.M.; Menat, S.; Agarwal, A.; Shah, D.; Patel, J. Comparative Evaluation of Efficacy of Physics Forceps versus Conventional Forceps in Orthodontic Extractions: A Prospective Randomized Split Mouth Study. J. Clin. Diagn. Res. 2016, 10, 41. [CrossRef] [PubMed] 
11. El-Kenawy, M.H.; Ahmed, W.M.S. Comparison Between Physics and Conventional Forceps in Simple Dental Extraction. J. Maxillofac. Oral Surg. 2015, 14, 949-955. [CrossRef] [PubMed]

12. ClinicalTrials.gov. Available online: https:/ / clinicaltrials.gov/ (accessed on 1 December 2021).

13. Misch, C.E.; Perez, H.M. Atraumatic extractions: A biomechanical rationale. Dent. Today 2008, 27, $100-101$.

14. Reilly, D.T.; Burstein, A.H. The elastic and ultimate properties of compact bone tissue. J. Biomech. 1975, 8, 393-405. [CrossRef]

15. El-Safory, N.S.; Fazary, A.E.; Lee, C.-K. Hyaluronidases, a group of glycosidases: Current and future perspectives. Carbohydr. Polym. 2010, 11, 165-181. [CrossRef]

16. Alexander, S.A.; Swerdloff, M.; Ceen, R.; Bertolami, C.N. Hyaluronidase activity in human premolar and third molar dental sacs. Arch Oral Biol. 1980, 25, 207-209. [CrossRef]

17. Dym, H.; Weiss, A. Exodontia: Tips and Techniques for Better Outcomes. Dent. Clin. N. Am. 2012, 56, 245-266. [CrossRef] [PubMed]

18. Mandal, S.; Gupta, S.; Mittal, A.; Garg, R. Collate on the ability of physics forceps v/s conventional forceps in multirooted mandibular tooth extractions. J. Dent. Med. Sci. 2015, 14, 63-66.

19. Senthoor, P.; Janani, K.; Ravindran, C. A Prospective, Randomized Double-Blinded Study to Evaluate the Efficacy of Buffered Local Anesthetics in Infected and Inflamed Pulp and Periapical Tissues. J. Maxillofac. Oral Surg. 2019, 19, 246-250. [CrossRef] [PubMed] 